\title{
Child Immunization Coverage - A Critical Review
}

\author{
${ }^{1}$ Sourabh Shastri ${ }^{* 2}$ Anand Sharma ${ }^{3}$ Prof. Vibhakar Mansotra \\ ${ }^{I}$ Department of Computer Science \& IT, Bhaderwah Campus, University of Jammu, J\&K, India \\ ${ }^{2,3}$ Department of Computer Science \& IT, University of Jammu, $J \& K$, India
}

\begin{abstract}
Immunization plays a vital role in the lives of children by protecting them against infectious diseases such as Measles, Polio, Tuberculosis, Hepatitis B, Diphtheria, whopping cough, Tetanus etc. There are different programmes and facilities for newborn and child health under National Health Mission (NHM). However, despite these schemes and programmes, India fares poorly when compared to other countries. In this research paper, we present a critical review of the various programmes, schemes and research currently being undergoing in child immunization.
\end{abstract}

Keywords: Immunization, Measles, Polio, Tuberculosis, Hepatitis B, Diphtheria, Tetanus etc.

\section{Introduction}

Children are the future of any country so their development is as significant as the development of other assets. Immunization is a vital part for the proper development of the children. Immunization is an easy, secure and efficient process of protecting individuals against the world's most infectious diseases by administering vaccines. Immunization reduces the spreading of diseases thus protects the society from harmful diseases. Immunization plays an essential role in the children's lives as a preventive health action because it protects them from most dangerous childhood diseases [1]. Immunization process will become more successful if the child receives full course of recommended immunization doses [2]. According to World Health Organization (WHO), Immunization currently averts an estimated 2 to 3 million deaths every year but an estimated 18.7 million infants worldwide are still missing out on basic vaccines [3]. Around the world, UNICEF and its partners like WHO, GAVI, the Vaccine Alliance, the US centres for Disease Control, the Bill \& Melinda Gates Foundation and others including numerous non-governmental organizations jointly act to ensure that vaccines protect all children, especially those hardest to reach and most in need [4].

Attention was given to immunization programme in India after the successful eradication of smallpox in mid 1970s. India has launched Expanded Programme on Immunization (EPI) for immunizing children against diphtheria, pertussis, tetanus and typhoid in 1978 mainly for the urban areas. Oral Polio Vaccine against polio, BCG against tuberculosis and vaccination against measles were included in 1979-80, 1981-82 and 1985-86 respectively [5].

The programme was revised in 1985 and renamed as Universal Immunization Programme (UIP) to protect all infants (0-12 months) against six diseases namely tuberculosis, diphtheria, pertussis, tetanus, poliomyelitis, and measles. In 1986, UIP was given the status of National Technology Mission. UIP became a part of Child Survival and Safe Motherhood (CSSM) programme in 1992. CSSM includes both UIP and Safe motherhood program. The UIP was integrated with Reproductive Child Health (RCH) programme in 1997 and became a key area under NRHM in 2005 [6]. Hepatitis B was added to the UIP in 2007. The details of vaccination under UIP are shown in table 1.

TABLE 1: Details of vaccination under UIP [6]

\begin{tabular}{|c|c|c|c|c|}
\hline Vaccine and Presentation & Protection & Route & $\begin{array}{l}\text { No. of } \\
\text { doses }\end{array}$ & Vaccination Schedule \\
\hline BCG (Lyophilized vaccine) & Tuberculosis & Intradermal & 1 & $\begin{array}{l}\text { At birth (upto } 1 \text { year if not given } \\
\text { earlier). }\end{array}$ \\
\hline $\begin{array}{l}\text { OPV } \\
\text { (Liquid vaccine) }\end{array}$ & Poliomyelitis & Oral & 5 & $\begin{array}{l}\text { Birth dose for institutional deliveries, } \\
\text { Primary three doses at } 6,10 \& 14 \text { week } \\
\text { and one booster dose at } 16-24 \text { month of } \\
\text { age. Given orally. }\end{array}$ \\
\hline Hepatitis B (Liquid vaccine) & Hepatitis B & Intramuscular & 4 & $\begin{array}{l}\text { Birth dose (within } 24 \text { hours) for } \\
\text { institutional deliveries, Primary three } \\
\text { doses at } 6,10 \text { \& } 14 \text { week. }\end{array}$ \\
\hline $\begin{array}{l}\text { DPT } \\
\text { (Liquid vaccine) }\end{array}$ & $\begin{array}{l}\text { Diphtheria, } \\
\text { Pertussis and } \\
\text { Tetanus }\end{array}$ & Intramuscular & 5 & $\begin{array}{l}\text { Three doses at } 6,10 \& 14 \text { week and two } \\
\text { booster doses at } 16-24 \text { month and 5-6 } \\
\text { years of age. }\end{array}$ \\
\hline $\begin{array}{l}\text { Measles (Lyophilized } \\
\text { vaccine) }\end{array}$ & Measles & Subcutaneous & 2 & $\begin{array}{l}9-12 \text { months of age and } 2 \text { nd dose at } 16- \\
24 \text { months. }\end{array}$ \\
\hline $\begin{array}{l}\text { TT } \\
\text { (Liquid vaccine) }\end{array}$ & Tetanus & Intramuscular & $\begin{array}{l}2 \\
2\end{array}$ & $\begin{array}{l}10 \text { years and } 16 \text { years of age. } \\
\text { For pregnant women, two doses given }\end{array}$ \\
\hline
\end{tabular}




\begin{tabular}{|l|l|l|l|l|}
\hline & & & & $\begin{array}{l}\text { (one dose if previously vaccinated } \\
\text { within three year). }\end{array}$ \\
\hline JE (Lyophilized vaccine) & $\begin{array}{l}\text { Japanese } \\
\text { Encephalitis } \\
\text { (Brain Fever) }\end{array}$ & Subcutaneous & 2 & $\begin{array}{l}9-12 \text { months of age and 2nd dose at 16- } \\
24 \text { months (6 months after vaccination } \\
\text { drive). }\end{array}$ \\
\hline $\begin{array}{l}\text { Hib } \\
\text { (Liquid vaccine) }\end{array}$ & $\begin{array}{l}\text { Hib Pneumonia } \\
\text { and Hib } \\
\text { meningitis }\end{array}$ & Intramuscular & 3 & $6,10 \& 14$ week of age. \\
\hline
\end{tabular}

Immunization division at Ministry of Health and Family Welfare (MoHFW) provides all the technical assistance required to undertake the activities under UIP. The primary responsibility of this unit comprise actions connected to Routine Immunization, Campaigns (SIAs) such as Polio, Measles, and Japanese Encephalitis, Monitoring Adverse Events Following Immunization (AEFI), Vaccine and Cold Chain Logistics, Strategic communication related to immunization program and trainings related to Immunization Program [6].

Adverse Events Following Immunization (AEFI) surveillance system was initiated in 1988 in India. It monitors immunization safety, detects and responds to any adverse events and improves the quality of immunization in India. The national AEFI guidelines were published in 2005 which have then been revised in 2010 and then these guidelines have been disseminated all over the country to medical officers.

According to National Health Mission, Ministry of Health \& Family Welfare, Government of India, the total financial expenditure for routine immunization for 2014-15 was Rs 1068.10 crore as budget estimate and Rs. 740 crore as revised estimate. The budget estimate for the year 2015-16 is Rs. $700 \mathrm{cr}$. This includes the cost for the vaccine, syringes, cold chain and operational cost provided to the states/UTs under Program Implementation Plans (PIP) [7]. The full immunization coverage as assessed by various surveys is shown in table 2.

TABLE 2: Different Surveys [7]

\begin{tabular}{|c|c|c|}
\hline Source & Coverage Evaluation Survey (CES 2009) & Rapid Survey on Children (RSOC 2013-14) \\
\hline Full Immunization & 61.0 & 65.3 \\
\hline BCG & 86.9 & - \\
\hline OPV3 & 70.4 & - \\
\hline DPT3 & 71.5 & 74.7 \\
\hline Measles & 74.1 & 78.8 \\
\hline No Immunization & 7.6 & 6.7 \\
\hline
\end{tabular}

Mission Indradhanush was launched by Ministry of Health and Family Welfare (MoHFW) on December 25, 2014 as a programme all over the country to vaccinate all unimmunized and partially immunized children and pregnant women by 2020 under the UIP that are missing during the schedule immunization programmes. The main objective of the mission is to fully immunized all children under the age of two years against seven life-threatening but vaccine-preventable diseases namely: Diphtheria, Pertussis (Whooping Cough), Tetanus, Tuberculosis, Polio, Hepatitis B and Measles which increased by only $1 \%$ a year from 2009 to 2013, from 61\% to 65\%. Besides, vaccines for Japanese Encephalitis (JE) and Haemophilus influenzae type B (HIB) are also being provided in selected states. The motive of mission Indradhanush is to increase full immunization coverage from 65\% in 2013 to $90 \%$ children of the country in next five years. Initially, 201 High Focus Districts were selected for the first phase that has utmost number of unimmunized and partially immunized children. There were total four rounds and 9.4 lakh sessions in the first phase where about 2 crore vaccines were given to the children and pregnant women. 352 districts have been selected for the second phase of mission Indradhanush including 279 mid-priority districts, 33 from North-East states and 40 districts from the phase one, where large number of missed-out children was selected [8].

A nation with healthy children is more capable of achieving goals because today's children are nation builders of tomorrow for making the country vibrant and flourishing. So the health of the children should be given priority in the policies of the government. In this way, Immunization is one of the powerful tool and basic need in the lives of children.

\section{Review Analysis}

India is the country that accommodates the maximum number of children in the world. India itself contributes to more than 20 percent of the world's child deaths, with approximately 1.73 million children dying annually before completing their fifth birthday [9]. The main purpose of this research paper is to present a survey on the research performed in the field of child immunization. The research papers were thoroughly reviewed and we extracted the goals achieved, schemes implemented and various techniques applied in child immunization databases. 
Farha Azmi and Dr. Ratna Prakash [10] in their study assessed the knowledge of immunization among mothers of under-5 children of Uttar Pradesh state. They have concluded according to their research approach that most of the mothers of under-5 children have poor knowledge of immunization.

PCTS (Pregnancy, Child Tracking \& Health Services Management System) [11] is an online web based service provided by the Government of Rajasthan for facilitating the citizens. The system tracks pregnant women, infants and children online for providing the proper services and monitoring the immunization programme to reduce maternal and infant mortality. Swasthya Sandesh Seva is used to send sms alerts to the citizens and health workers.

Government of India [6] has launched mission Indradhanush on $25^{\text {th }}$ December 2014 as a particular drive to immunize all children and pregnant women who have either not received any vaccination or partially vaccinated under Universal Immunization Programme by 2020.

Puneet Kumar and Dharminder Kumar [12] proposed a conceptual model using ICT to improve the process of child immunization in India. Aadhar is used to register the infants and every health centre should be equipped with a child registration unit to register the children for immunization. They have also compared their framework with PCTS service provided by the Government of Rajasthan.

Debjani Barman and Arijita Dutta [13] examined the month-specific immunization coverage in West Bengal by using DLHS-3 2007-08 data and concluded that only $20 \%$ month-specific coverage stands but the non-month specific coverage is $75 \%$. Thus more determined preparation is required for the enhancement of month-specific coverage in West Bengal.

Dr. M. Hemalatha and S. Megala [14] examined immunization data of children by applying decision tree and Artificial Neural Network. In their study, for the doses of OPV2, OPV3, DPT3 and MCV, uptake in male's children is approximately $1 \%$ higher than in females children and in DPT1, females children have higher uptake of $41.4 \%$ than males children of $39.2 \%$.

Mohitulameen Ahmed Mustafi and Dr. Mir Mohammad Azad [2] examined the factors like socioeconomic, demographic, cultural, community and behavioural affecting the status of immunization of children under five in Bangladesh. They have developed a conceptual framework having three sets of factors i.e. factors associated with clients, health care providers and demographic, socio-cultural and community variables having relationship with acceptance of immunization. Their analysis resulted that the children who have chances of getting full immunization are the children whose parents are educated, service holders, children of respondents who had no work, current age of respondents whose age is 21-30 years, highest education level of respondent, the respondents who had used tube well water and children who come from better economic status households.

Abhishek Kumar and Sanjay K. Mohanty [15] examined the socio-economic differentials in coverage of basic childhood immunization in India. They have used bivariate, multivariate and progression rate to understand the differentials and changes in child immunization. Data for the survey has been taken from three rounds of NFHS conducted during 1992-2006. All three rounds have covered 99\% of India's population. Full immunization increased from $35 \%$ in $1992-93$ to $44 \%$ in $2005-06$, partial immunization increased from $35 \%$ to $51 \%$ and a decline in no immunization from $30 \%$ in $1992-93$ to $14 \%$ in $1998-99$ and $5 \%$ in 2005-06. Special effort is needed for the coverage of DPT and measles vaccines as coverage of these vaccines is lower as compared to polio.

A M Kadri et. al. [16] studied the immunization coverage among children aged 12-23 months in urban slums of Ahmedabad city. Cross-sectional study was conducted that included 138 children from 1800 households. Children who have received 1 dose of BCG, 3 doses of DPT and OPV and 1 dose of measles were considered full immunized. The children who have missed 1 or more doses from these is considered as partially immunized and the children who did not receive even a single dose of vaccine are considered as no immunized. They have found that the coverage of vaccines was high for BCG, DPT-1 and OPV-1 i.e. $83.3 \%$ and low for measles i.e. $71.7 \%$. The coverage rate was slightly high among male children than female children for all the vaccines. Full immunization coverage is low due to not immunize with measles vaccination.

Adebayo Peter Idowu et. al. [17] presented a mathematical model for predicting immunizable diseases in Nigeria that affect children between age 0-5 years. They have applied three data mining techniques namely ANN, Decision tree and Naïve Bayes Classifier to uncover hidden information. Their study collected data from six immunizable diseases namely: Measles, Tuberculosis, Polio, Yellow Fever, Pertussis and Hepatitis B. They also argued that if a predictive model is introduced, the programme of immunization will be strengthened.

M. Mamatha and V. Nageswara Rao [18] explored the vaccination coverage among children aged 0-9 months using NFHS- III data and analyzed by chi-square test to find out the results using SPSS. Out of total population, $12.4 \%$ are still not been vaccinated. Non-utilization of vaccines is found to be $9.1 \%$ among the total urban and $14.2 \%$ among the total rural population. The non-coverage rate of vaccines is observed to be slightly high in female children i.e. $12.9 \%$ than their male counterparts i.e. $12 \%$.

Dr. Lokesh Kumar Sonkaria et. al. [19] examined the immunization status of 1 to 5 years children of a rural area of Rajasthan. They have carried out a community based cross-sectional descriptive study of 330 
sample size. They have founded that out of 330 children, 248 (75.15\%) children were fully immunized i.e. those children who receive one dose of BCG, one dose of Measles, three doses of OPV and three doses of DPT vaccines up to 1 year of age, $60(18.18 \%)$ were partially immunized i.e. those who have missed any one of the doses and $22(6.67 \%)$ were unimmunized i.e. those who have not received any type of vaccination.

Bhuwan Sharma et. al. [20] examined the role of socio demographic variables on immunization coverage. They have used WHO's 30 cluster sampling method for the evaluation of immunization coverage and selected seven subjects between age group of 12-23 months from each of 30 clusters so therefore final sample size consists of 210 children. In their study area, $170(81 \%)$ children received complete immunization, 37 (17.6 $\%)$ children received partially immunization and $3(1.4 \%)$ children did not receive any type of immunization. The coverage of BCG dose was found highest $(97.1 \%)$ while Hepatitis was lower than that of OPV and DPT. Measles coverage is also less than $90 \%$. The major reasons of low vaccination coverage were children illness, lack of knowledge, low education of mother, high birth order and place of delivery.

Danish and Ayaz Muhammad [21] examined the relationship between child immunization of children aged 12-23 months and household socio-demographic characteristics in Pakistan. They have applied chi-square test and logistic regression on the household level data from Pakistan Social and Living Standard Measurement Survey. In their conceptual framework, child immunization is considered as dependent variable while the gender, parents education, area and province or region are taken as independent variables. The sample size for all provinces has been fixed at 76546 households selected from 5413 sample villages or enumerated blocks. Their results showed that the male children are more immunized as compare to female children, people in urban area more likely to immunize their children as compare to people in rural area. In case of child immunization, not only child's age but also child's gender, resident of the child, parents education, household income, family size plays a vital role.

Rachna Kapoor and Sheetal Vyas [22] examined the awareness and knowledge of mothers of under five children regarding immunization in Ahmedabad. The primary sources of knowledge of mothers about vaccine preventable diseases were anganwadi workers and television. In their cross sectional descriptive study, $85 \%$ of the women were aware of poliomyelitis, $15 \%$ women were aware of Hepatitis B and 10\% women were aware of pertusis as a vaccine preventable disease. Even $80 \%$ women had no knowledge of vitamin A.

Jisy Jose et. al. [23] observed the awareness on immunization among mothers of under five children with non-experimental exploratory survey. They have collected the data by using base line performa and structured knowledge questionnaire. In their survey they have found that $30 \%$ of mothers have poor knowledge of immunization while $43.4 \%$ had average knowledge, $23.4 \%$ had good knowledge and $3.33 \%$ mothers had excellent knowledge of immunization. They have concluded on the basis of their result that there was a significant association between knowledge and exposure to mass media in relation to immunization among mothers of under five children.

Tufeel Ahad Baba et. al. [24] examined the utilization of maternal and child health services at sub centre level by target population in a sub centre area. They have found in their survey of 671 cases that $40.5 \%$ mothers had taken their children at sub centre for immunization. $67.66 \%$ children received complete immunization at sub centre and $32.33 \%$ children received incomplete immunization at sub centre.

Rahul Sharma and Sanjiv K Bhasin [25] assessed the knowledge about routine immunization among caretakers of young children. In their cross-sectional study, 682 caretakers accompanying children under 5 years were considered and proportions and chi-square test have been applied for the results. Out of 682 caretakers, only 268 caretakers were aware of three diseases covered under routine immunization. They concluded that there is an urgent need to aware caretakers about routine immunization.

Payyappat Sabin Shivan et. al. [26] worked on a project named as Pre-Baby vaccination to provide vaccination notifications and reminders as SMS to the families of newborn and pregnant women at regular intervals by using their registered id. In the proposed system K-means clustering algorithm has been used and the families can access the static information send by the system as a notification periodically.

\section{Tables}

Table 3, Table 4, Table 5 and Table 6 depicts the techniques used, areas covered, data used, and sociodemographic variables/factors used in papers respectively.

TABLE 3: Techniques Used in Papers

\begin{tabular}{|c|c|}
\hline Techniques & Papers \\
\hline Non Experimental Survey Method & 10,23 \\
\hline Convenient Sampling Method & 10 \\
\hline Decision Tree & 14,17 \\
\hline Artificial Neural Network & $2,17,18,21,25$ \\
\hline Chi-Square Test & 15 \\
\hline Bivariate, Multivariate and Progression Rate & 16 \\
\hline Cluster Survey & \\
\hline
\end{tabular}


Child Immunization Coverage - A Critical Review

\begin{tabular}{|c|c|}
\hline Naïve Bayes Classifier & 17 \\
\hline Thirty Cluster Sampling Technique & 19,20 \\
\hline Multistage Sampling & 24 \\
\hline
\end{tabular}

TABLE 4: Coverage Area in India and Other Countries

\begin{tabular}{|c|c|}
\hline Area & Papers \\
\hline Uttar Pradesh & 10 \\
\hline West Bengal & 13 \\
\hline Bangladesh & 2 \\
\hline India & 15,18 \\
\hline Bihar & 15 \\
\hline Gujrat & 15 \\
\hline Ahmedabad & 16,22 \\
\hline Nigeria & 17 \\
\hline Rajasthan & 19 \\
\hline Pakistan & 21 \\
\hline Mangalore & 23 \\
\hline Kashmir & 24 \\
\hline East Delhi & 25 \\
\hline
\end{tabular}

TABLE 5: Data used in Papers

\begin{tabular}{|c|c|}
\hline Data & Papers \\
\hline BDHS 2004 & 2 \\
\hline NFHS 1992-2006 & 15 \\
\hline Survey Data & 10,16 \\
\hline NFHS -3 & 18 \\
\hline Household level data (PSLM 2010-11) & 21 \\
\hline DLHS-3 (2007-08) & 13 \\
\hline
\end{tabular}

TABLE 6: Socio-Demographic Variables/Factors used in Papers

\begin{tabular}{|c|c|}
\hline Socio-Demographic Variables/Factors & Papers \\
\hline Religion & $2,10,13,15,21,23$ \\
\hline Area/Place of Residence & $10,13,15,21$ \\
\hline Educational Status & $10,13,21,22,23$ \\
\hline Monthly Family Income & $10,13,21,23$ \\
\hline Sex & $2,13,15,21$ \\
\hline Age & 2,21 \\
\hline Employment/Occupation & $13,22,23$ \\
\hline Age of Mother & $15,22,23$ \\
\hline Family Size & 21 \\
\hline Source of Information & 23 \\
\hline Exposure to Mass Media & 23 \\
\hline
\end{tabular}

\section{Conclusion}

Immunization is the most economic and most efficient solution to prevent children from infectious diseases. This paper aimed to explore the goals achieved, schemes implemented, techniques used, data used, areas covered, and socio-demographic factors used in the domain of child immunization. The paper explored the reasons why new born babies missed immunization schedules. In the result, we have reviewed that the reasons for missing immunization are bad health of children, parent's knowledge of immunization, family size, household income, place of delivery, high birth rate, low education status of mother etc. The factors for full immunization discovered in the papers are children whose parents are educated, children of parents who has a service holder, current age of respondents whose age is 21-30 years, highest education level, drinking water from tube well and who comes from better economic status households. Some researchers proposed conceptual frameworks using ICT to improve the process of child immunization while others examined by applying statistical and data mining techniques on immunization data to understand the differentials and changes in child immunization. The Government of India has launched the mission Indradhanush to immunize all children and pregnant women by 2020 under universal immunization programme. The Government of Rajasthan facilitated PCTS web based application for tracking pregnant women and children for providing services.

\section{Future Scope}

There has been enormous progress achieved till now but still there is a need to extract knowledge from the child immunization data for the improvement of quality. In the future, we shall apply different ICT and data mining techniques on child immunization data to discover the interesting patterns and knowledge for the welfare of the society. 


\section{References}

[1]. The UNICEF website. [Online]. Available: http://www.unicef.org/immunization/

[2]. Mohitulameen Ahmed Mustafi and Dr. Mir Mohammad Azad, "Factor Influencing of Child Immunization in Bangladesh," International Journal of Mathematics and Statistics Studies, vol. 1, no. 3, pp. 55-65, September 2013.

[3]. The WHO website. [Online]. Available: http://www.who.int/mediacentre/factsheets/fs378/en/

[4]. The UNICEF website. [Online]. Available: http:/www.unicef.org/immunization/files/Immunization_brochure.pdf

[5]. Suresh Sharma, "Immunization Coverage in India," Working Paper Series No. E/283/2007, Institute of Economic Growth, Delhi, India.

[6]. The MOHFW website. [Online]. Available: www.mohfw.nic.in/.../1892s/Immunization_UIP.pdf

[7]. The NHM website. [Online]. Available: http://nrhm.gov.in/

[8]. The NHP India website. [Online]. Available: http://www.nhp.gov.in/1mission-indradhanush_pg

[9]. The UNICEF website. [Online]. Available: http://unicef.in/Uploads/Resources/CPAP_2013-17(1).pdf

[10]. Farha Azmi et. al., "Assessment of Knowledge towards Immunization among Mothers of Under - Five of U.P India: A Quantitative Approach (Original Study)," International Journal of Science and Research, vol. 4, issue 2, pp. 1898-1900, February 2015.

[11]. The PCTS Rajasthan website. [Online]. Available: http://pctsrajmedical.raj.nic.in/private/login.aspx.

[12]. Puneet Kumar and Dharminder Kumar, "A Conceptual E-Governance Framework for Improving Child Immunization Process in India,” International Journal of Computer Applications, vol. 69, no. 1, pp. 39-43, May 2013.

[13]. Debjani Barman and Arijita Dutta, "Access and Barriers to Immunization in West Bengal, India: Quality Matters," Journal of Health, Population and Nutrition, vol. 31, no. 4, pp. 510-522, December 2013.

[14]. Dr. M. Hemalatha and S. Megala, "Mining Techniques in Healthcare: A Survey of Immunization," Journal of Theoretical and Applied Information Technology, vol. 25, no. 2, pp. 63-70, March 2011.

[15]. Abhishek Kumar and Sanjay K. Mohanty, "Socio-economic differentials in childhood immunization in India, 1992-2006," Journal of Population Research, vol. 28, no. 4, pp. 301-324, August 2011.

[16]. A. M. Kadri et. al., "Study on Immunization Coverage in Urban Slums of Ahmedabad City," Health and Population: Perspectives and Issues, vol. 33, no. 1, pp. 50-54, 2010.

[17]. Adebayo Peter Idowu et. al., "Data Mining Techniques for Predicting Immunize-able Diseases: Nigeria as a Case Study," International Journal of Applied Information Systems, vol. 5, no. 7, pp.-5-15, May 2013.

[18]. M. Mamatha and V. Nageswaro Rao, "Immunization Coverage in India: A Study by using NFHS- III Data," Indian Journal of Applied Research, vol. 5, no. 12, pp.-531-533, December 2015.

[19]. Dr. Lokesh Kumar Sonkaria et. al., "Immunization Status of 1 to 5 Year Children of A Rural Population in Rajasthan, India," Indian Journal of Applied Research, vol. 6, no. 1, pp.-599-600, January 2016

[20]. Bhuwan Sharma et. al., "Immunization Coverage: Role of Sociodemographic Variables," Advances in Preventive Medicine, vol. 2013, article id. 607935, pp. 1-5, 2013.

[21]. Danish and Ayaz Muhammad, "Relationship between Child Immunization and Household Socio-Demographic Characteristic in Pakistan," Research on Humanities and Social Sciences, vol. 4, no. 7, pp. 82-89, 2014.

[22]. Rachna Kapoor and Sheetal Vyas, "Awareness and Knowledge of mothers of under five children regarding immunization in Ahmedabad," Healthline, vol. 1, no. 1, pp. 12-15, July-Dec 2010.

[23]. Jisy Jose et. al., "Awareness on Immunization among Mothers of Under five children," International Journal of Innovative Research and Development, vol. 2, no. 6, pp. 620-627, June 2013.

[24]. Tufeel Ahad Baba et. al., "An Epidemiological Study to Assess the Utilization of Maternal and Child Health Care Services at SubCenter Level by the Target Population in Northern India, Kashmir Valley," International Journal of Medical Science and Public Health, vol. 2, no. 3, pp.679-687, 2013.

[25]. Rahul Sharma and Sanjiv K Bhasin, "Routine Immunization - Do People Know About It? A Study Among Caretakers of Children Attending Pulse Polio Immunization in East Delhi," International Journal of Community Medicine, vol. 33, no. 1, pp. 31-34, Jan. 2008.

[26]. Payyappat Sabin Shivan et. al., "Pre-Baby Vaccination," International Journal of Interdisciplinary Research, vol. 2, no. 5, pp. 49$51,2016$. 